http://jmscr.igmpublication.org/home/ ISSN (e)-2347-176x ISSN (p) 2455-0450 crossref DOI: https://dx.doi.org/10.18535/jmscr/v9i11.21

\author{
Journal Of Medical Science And Clinical Research

\title{
A Prospective Study in Scrub Typhus Patients with Cardiac Manifestationsin- A Tertiary Care Center
}

\author{
Authors \\ Dr Divya Yeedulamudi, Dr K. Sudheer, Dr K. Mahendran \\ GEMS, Srikakulam, Andhra Pradesh, India
}

\section{Introduction}

Scrub typhus, a rickettsial infection caused by Orientia Tsutsugamushi

Typhus remains a substantially under-recognized disease entity, particularly in Asia, where up to $28 \%$ of malaria negative fevers can be attributed to rickettsial infections

The clinical manifestations of this disease range from sub-clinical disease to organ failure and death. Jaundice, renal failure, pneumonitis, ARDS, septic shock, myocarditis and meningoencephalitis are various known complications of this disease

In south East Asia alone, an estimated 1 million cases of scrub typhus occur yearly with approximately 50000-80000 deaths per year

Scrub typhus contributing to myocardial disease and death is not well established Myocarditis occurs due to disseminated endothelial infection of the small vessels or by secondary immune mediated mononuclear inflammation

\section{Aim \& Objectives}

1. To study the spectrum of cardiac manifestations in scrub typhus infection

2. To evaluate the incidence of myocarditis

3. To compare the outcome of scrub typhus patients with and without myocarditis

\section{Materials \& Methods}

\section{Source of Data}

The study was conducted on 81 patients admitted in Great Eastern Medical School \& Hospital, Ragolu, Srikakulam, Andhra Pradesh, with scrub IgM ELISA positive

Study Period: August 2019 to November 2020

Study Design: Prospective cohort study

Inclusion Criteria

1) Age more than 16 years

2) Acute febrile illness (AFI) with criteria fulfilled for the diagnosis of scrub typhus

3) Absence of any obvious focus of infection after initial clinical evaluation

Criteria For Diagnosis: Positive for Scrub IgM ELISA or having eschar on body and negative for other serology like Dengue, Malaria etc

\section{Exclusion Criteria}

1) Alternative diagnosis other than scrub typhus

2) Patients diagnosed with autoimmune disorders

3) Seropositive for both Scrub \& Dengue

\section{Statistical Analysis}

Categorical and continuous variables were compared for outcome by using the fisher's exact test and student $\mathrm{t}$ test respectively 


\section{JMSCR Vol||09||Issue||11||Page 111-113||November}

$\mathrm{p}$ value of $<0.05$ was considered statistically significant for all analysis

\section{Result}
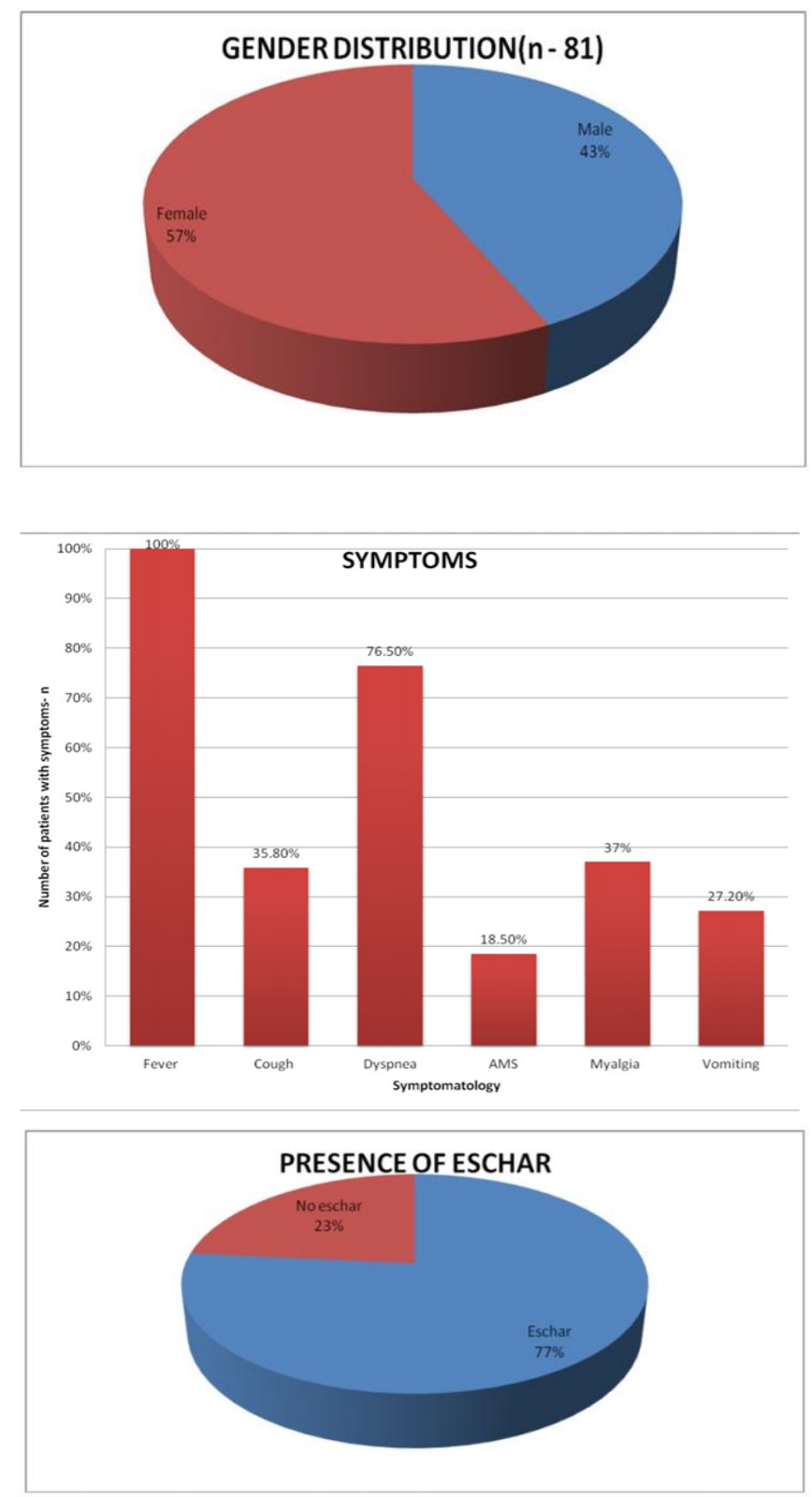

PERCENTAGE OF DIFFERENT ORGAN INVOLVEMENT IN SCRUB TYPHUS (n-81)

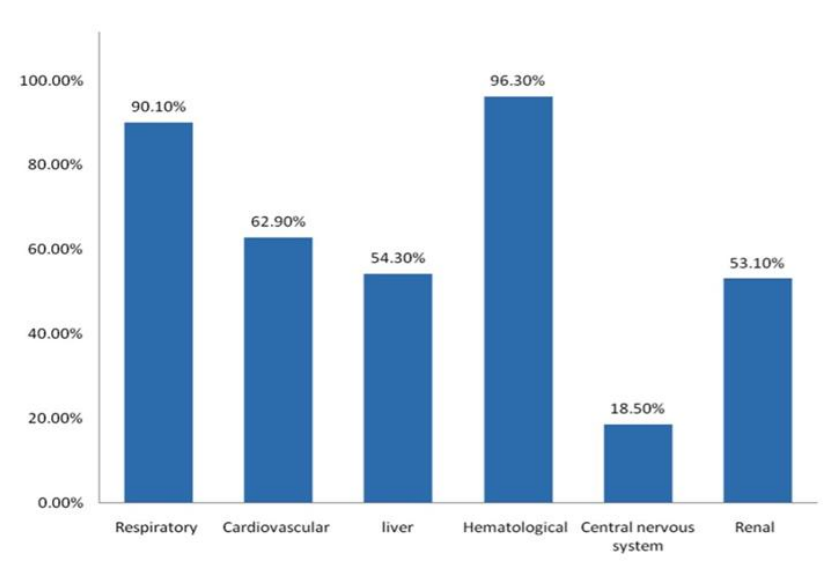

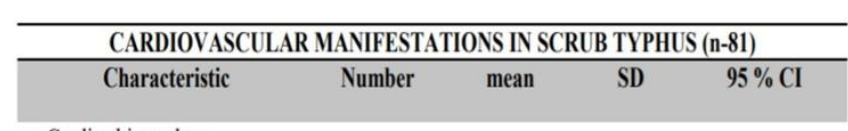

a. Cardiac biomarkers

\begin{tabular}{lcccc} 
CKMB & 81 & 6.69 & 9.4 & $4.88-9.07$ \\
Troponin T & 81 & 83.1 & 212.2 & $36.21-130.04$ \\
b. Echocardiography findings & & & & \\
LVEF & 81 & 57.59 & 14.16 & $54.46-60.72$ \\
Cardiac output & 63 & 4.37 & 1.38 & $4.02-4.71$ \\
\hline
\end{tabular}

ELECTROCARDIOGRAPHIC FINDINGS IN SCRUB TYPHUS

\begin{tabular}{lc}
\hline Sinus Tachycardia & $38(46.9)$ \\
ST-T changes & $10(12.3)$ \\
T wave inversion & $8(9.9)$ \\
QRS morphology changes & $11(13.6)$ \\
Supraventricular tachycardia & $1(1.2)$ \\
\hline Atrial fibrillation & $3(3.7)$ \\
\hline Wide QRS tachycardia & $1(1.2)$ \\
Sinus bradyarrhythmia & $5(6.2)$
\end{tabular}
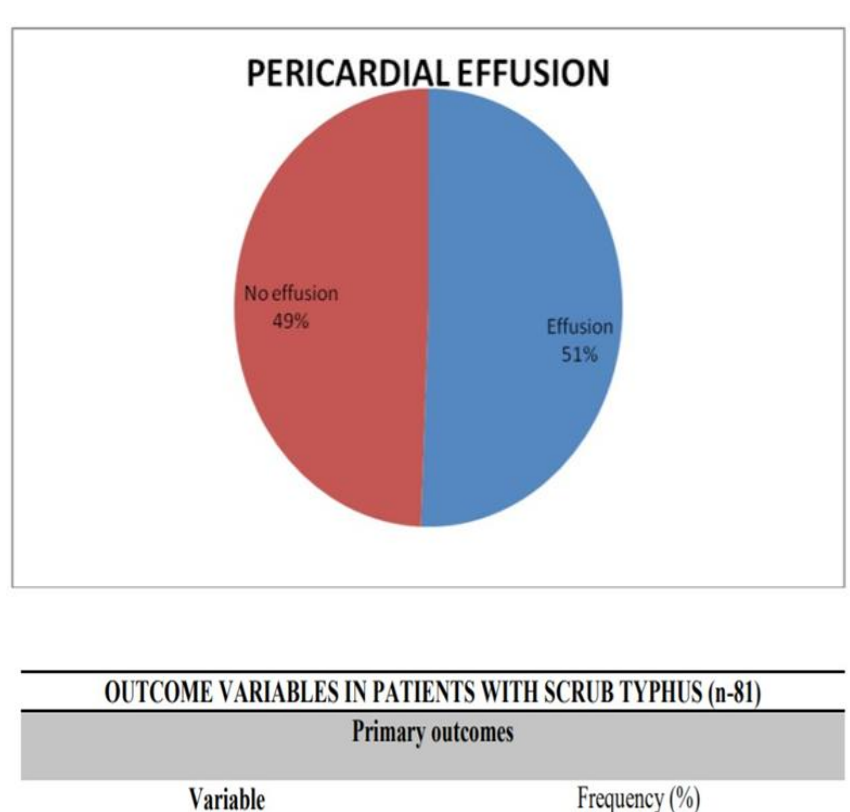

\begin{tabular}{lc} 
Myocarditis & $17(21)$ \\
\hline Myocardial dysfunction & $25(30.9)$ \\
Myocardial injury & $50(61.7)$
\end{tabular}




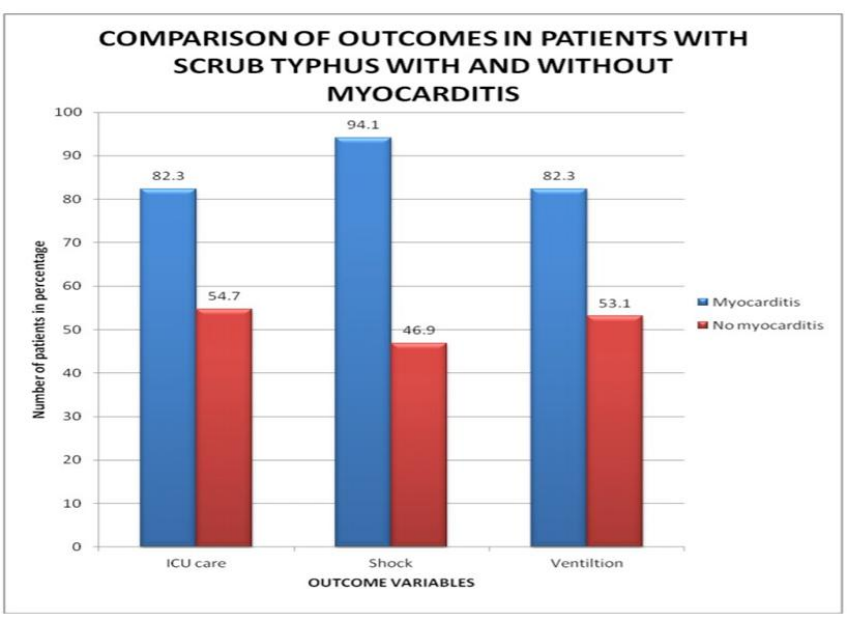

\section{Discussion}

The cardiovascular manifestations were assessed with the help of cardiac biomarkers, electrocardiogram and echocardiogram. The mean (SD) $\mathrm{CKMB}$ and troponin $\mathrm{T}$ values were $6.69 \pm$ $9.4 \mathrm{ng} / \mathrm{ml}$ and $83.1 \pm 212.2 \mathrm{pg} / \mathrm{ml}$.

Echocardiography was done in all patients. The mean \pm SD of LVEF was $57.59 \pm 14.16 \%$. The mean $\mathrm{CO}$ was $4.37 \pm 1.38$ liters

In this cohort 38 patients $(46.9 \%)$ had sinus tachycardia

In our cohort we found pericardial effusion in 41 patients $(51 \%)$

Regional wall motion abnormality was seen in 12 patients, in which 7 patients had myocarditis

The mean \pm SD duration of ICU and hospital days was $4.2 \pm 4.4$ and $9.2 \pm 4.7$ respectively

The patients requiring invasive and non invasive ventilation were $63.8 \%$ and $17.2 \%$ respectively

The crude mortality in our cohort was $9.9 \%$

\section{Conclusion}

In our cohort of scrub typhus patients from GEMS hospital the prevalence of myocarditis was $21 \%$ Myocardial injury was seen in $61.7 \%$ and myocardial dysfunction was observed in $30.9 \%$ participants

ECG changes were no specific; sinus tachycardia was the predominant ECG finding
The development of myocarditis increased the need for ventilation, prolonged the duration of ICU and hospital stay

Myocarditis was not associated with worse mortality in our cohort

\section{References}

1. Parola P, Raoult D. Tropical rickettsioses. Clin Dermatol 2006c;24:191-200.

2. Manosroi J, Chutipongvivate S, Auwanit $\mathrm{W}$, et al. Determination and geographic distribu- tion of Orientia tsutsugamushi serotypes in Thailand by nested polymerase chain reaction. Diagn Microbiol Infect Dis 2006;55:185-90.

3. Phongmany S, Rolain J-M, Phetsouvanh $\mathrm{R}$, et al. Rickettsial infections and fever, Vientiane, Laos. Emerg Infect Dis 2006;12:256-62.

4. Rosenberg R. Drug-resistant scrub typhus: Paradigm and paradox. Parasitol Today 1997; 13:131-2.

5. Seong SY, Choi MS, Kim IS. Orientia tsutsugamushi infection: overview and immune responses. Microbes Infect Inst Pasteur. 2001 Jan;3(1):11-21.

6. Korff S, Katus HA, Giannitsis E. Differential diagnosis of elevated troponins. Heart. 2006 Jul;92(7):987-93.

7. Varghese GM, Trowbridge P, Janardhanan J, Thomas K, Peter JV, Mathews P, et al. Clinical profile and improving mortality trend of scrub typhus in South India. Int $\mathbf{J}$ Infect Dis. 2014 Jun;23:39-43.

8. Griffith M,Peter J, Karthik G, Kalki R, Chrispal A, Pichamuthu K, Iyyadurai R, et al. Profile of organ dysfunction and predictors of mortality in severe scrub typhus infection requiring intensive care admission. Indian $\mathbf{J}$ Crit Care Med. 2014;18(8):497. 